\title{
Martensitic transformations of Cu-Al-Ni single crystals in tension/compression
}

\author{
V. Novak, P. Sittner and J. Van Humbeeck ${ }^{1}$ \\ Institute of Physics, Academy of Sciences of the Czech Republic, Na Slovance 2, \\ 18221 Prague 8, Czech Republic \\ ${ }^{1}$ MTM Department, Catholic University of Leuven, De Croylaan 2, 3030 Heverlee, Belgium
}

\begin{abstract}
Cu-Al-Ni alloys, similarly as other $\mathrm{Cu}$-base shape memory alloys, transform into more martensitic structures $\alpha_{1}{ }^{\prime}(6 \mathrm{R}), \beta_{1}^{\prime}(18 \mathrm{R})$ and $\gamma_{1}^{\prime}(2 \mathrm{H})$, depending on the temperature, stress, load axis orientation, sense of loading and composition. The transformation stress-temperature conditions at which individual transitions take place are beneficially represented in so called non-equilibrium stress-temperature phase diagrams. On the basis of the $\sigma-T$ diagrams, complex history dependent thermomechanical behaviors of SMA single crystals undergoing sequentially multiple solid state transitions can be easily understood and predicted. Since chemical composition of the alloy crystals affects mainly the equilibrium transformation temperatures, $T_{0}$ and only slightly the slopes of the transformation lines in the $\sigma-T$ diagrams, the diagrams mainly shift in the temperature range (over $\sim 200 \mathrm{~K}$ ) with the compositional variations. The shape of the diagrams, however, may change significantly when the $T_{0}$ shifts for individual transitions are different. Knowledge of the compositional dependence of $\sigma-T$ diagrams would be beneficial for the development of shape memory alloys with specific required thermomechanical properties. The aim of the present work is experimental investigation of the martensitic transformations and construction of the $\sigma-T$ diagram for $\mathrm{Cu}-\mathrm{Al}-\mathrm{Ni}$ alloy with lower $\mathrm{Al}$ content $\left(\mathrm{T}_{0}>363 \mathrm{~K}\right)$ and comparison with our previous results obtained on alloys with higher $\mathrm{Al}$ content $\left(\mathrm{T}_{0}<263 \mathrm{~K}\right)$.
\end{abstract}

\section{INTRODUCTION}

Since CuAlNi shape memory alloys, unlike the $\mathrm{CuZnAl}$, are quite resistant against martensite stabilization in the temperature range $373 \mathrm{~K}-473 \mathrm{~K}$, they are potential candidates for high temperature SMA's [1]. By adjusting properly the Al content, their transformation temperatures can be varied in the range 200-400K. However, reports on martensite stabilization effects in $\mathrm{CuAlNi}$ and similar Cu-based alloys during thermomechanical loads are worrying $[2,3]$. It is our opinion that care must be taken to make distinction between stabilization phenomena taking place due to irreversible structural changes, and apparent upward shifts of the reverse transformation temperatures due to the history dependent phenomena [4] originating from the hysteresis effects exhibited by individual phase transitions between $\beta_{1}$ austenite and $\alpha_{1}^{\prime}, \beta_{1}^{\prime}$ and $\gamma_{1}$ ' martensite phases in $\mathrm{Cu}-\mathrm{Al}-\mathrm{Ni}$ alloys. Depending on temperature, stress, load axis orientation, sense of load and history, various solid phases may exist and various transitions may occur in CuAlNi. There is thus no wonder that the history dependent phenomena are quite complex and can be easily confused with martensite stabilization especially when studied on polycrystalline alloys.

Recently, we have investigated systematically the effects of anisotropy [5] and tension/compression sense of load [6] on the martensitic transformations in oriented CuAlNi alloy single crystals with higher $\mathrm{Al}$ content $\left(\mathrm{M}_{\mathrm{s}} \sim 200 \mathrm{~K}\right)$ which transform to the $\gamma_{1}^{\prime}$ martensite phase upon stress free cooling. The results were presented in a form of stress-temperature non-equilibrium, $\sigma-\mathrm{T}$, diagrams which provide complete sets of information on transformation conditions and history dependent phenomena exhibited by the given crystals.

The aim of the present work is an experimental investigation of martensitic transformations in a [001] oriented single crystal of $\mathrm{Cu}-13.4 \mathrm{Al}-4.0 \mathrm{Ni}$ [wt.\%] alloy with lower $\mathrm{Al}$ content, and therefore with about $150 \mathrm{~K}$ higher transformation temperatures $\left(\mathrm{M}_{\mathrm{s}} \sim 365 \mathrm{~K}\right)$ compared to the alloys studied earlier (e.g. $\mathrm{Cu}-14.3 \mathrm{Al}-4.1 \mathrm{Ni}[\mathrm{wt} . \%])$. As was already mentioned, the alloys with lower Al contents are potential candidates for high temperature applications and thus have recently attracted new research attention. The goals were i) to find out whether the high temperature alloys exhibit the same kind of thermomechanical 
behavior as the previously studied alloys, ii) to establish the effect of composition on the tension/compression $\sigma-T$ diagram, and iii) to discuss possible consequences of the multiple martensitic transformations in $\mathrm{CuAlNi}$ for the high temperature applicability of the $\mathrm{Cu}$-based shape memory alloys.

\section{EXPERIMENTAL}

Single crystals of [100] oriented $\mathrm{Cu}-\mathrm{Al}-\mathrm{Ni}$, composition $4.0 \mathrm{wt} . \% \mathrm{Ni}$ and $13.4 \mathrm{wt} . \% \mathrm{Al}$, were obtained from ORIMI Steel (St. Petersburg). The DSC measurement (Perkin-Elmer 7) have shown that the as quenched crystals undergo a narrow hysteresis transformation with $M_{s}=365 \mathrm{~K}, A_{f}=371 \mathrm{~K}$ (Fig.1) that is known to be characteristic for the $\beta_{1} \rightarrow \beta_{1}^{\prime}$ cubic to monoclinic transformation in Cu-based SMA. Specimens for compression testing (length $12 \mathrm{~mm}$, diameter $4 \mathrm{~mm}$ ) and tension/compression testing (central part $l=10 \mathrm{~mm}, d=3 \mathrm{~mm}$ ) were prepared by spark cutting and electrochemical polishing.

Tension/compression stress-strain tests at constant temperature, thermal cycling tests at constant load, stress recovery tests as well as complex thermomechanical tests were performed on an INSTRON

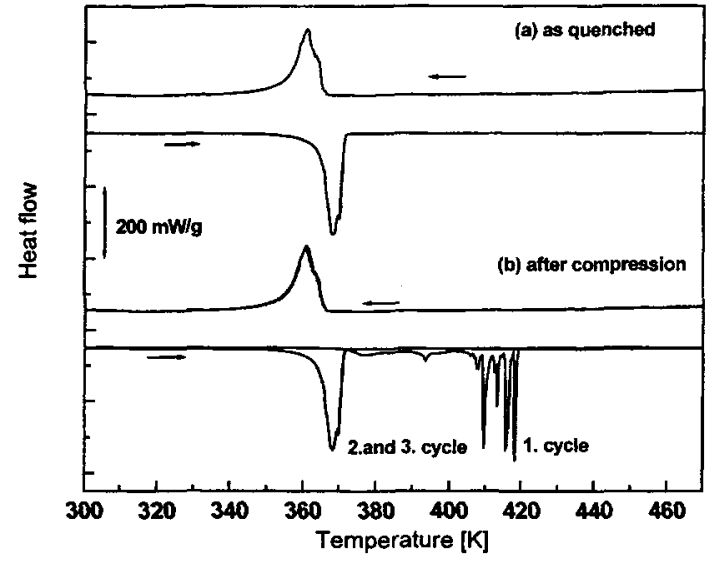

Figure 1: DSC thermal cycling of CuAlNi single crystal: a) heating-cooling of the virgin specimen b)

3 cycles of heating-cooling of the specimen deformed in compression at $T=295 \mathrm{~K}$.
1362 testing machine equipped with a heating/cooling chamber consisting of an electrical furnace and a cooling system by nitrogen vapors. Experiments were performed in position and/or load control mode and the strain was measured by an extensometer.

The single crystal transforms in reasonable approximation at constant stress level when the transformation is induced mechanically and at constant temperature when thermally induced. The transformations are observed as plateaus on the $\sigma-\varepsilon$ or $\varepsilon-T$ experimental curves. The stresses and temperatures corresponding to the plateau $\sigma$ - $T$ transformation conditions were evaluated and plotted as transformation lines in a non-equilibrium $\sigma-T$ diagram. When the observed responses could not be approximated by the plateaus, the $M_{s}$ and $A_{f}$ values were considered. The general method of the construction of the $\sigma$-T diagram from thermomechanical test data can be found in Ref. [7].

\section{RESULTS}

\subsection{Experimental evaluation of stress-temperature transformation conditions}

The response of the single crystal in tension and compression tests at high temperatures $T>400 \mathrm{~K}$ is shown in figure 2. In tension, the response of CuAINi single crystals is well known [8,9] to be due to the two successive stress induced $\beta_{l} \rightarrow \beta_{l}^{\prime}$ and $\beta_{l}^{\prime} \rightarrow \alpha_{l}^{\prime}$ transformations. Particularly for the presently studied crystal, the tensile stress induced MT's are reported in [10]. Less known is the behavior in compression [5], where the $\beta_{I} \rightarrow \beta_{1}^{\prime}$ closely followed by $\beta_{I} \rightarrow \beta_{I}^{\prime} \rightarrow \gamma_{1}^{\prime}$ transformation is responsible for the stress-strain curves of the character demonstrated in figure $2 \mathrm{~b}$. At the onset of the straining, only the $\beta_{l}{ }^{\prime}$ martensite is induced, which is clearly evidenced by the narrow hysteresis partial stress-strain curves. The more the crystal is further strained, the more the $\gamma_{1}^{\prime}$ phase becomes stress induced, and the wider is the stress hysteresis. The final phase achieved at transformation strain $\varepsilon \sim 8 \%$ is a single crystal of the $\gamma_{l}^{\prime}$ martensite. Upon subsequent stress free heating, this martensite single crystal transforms back to the austenite phase 
at $T \sim 450 \mathrm{~K}$ (about $80 \mathrm{~K}$ above the $A_{f}=371 \mathrm{~K}$ determined in DSC) very fast and with a lot of noise. The critical strain, at which the $\gamma_{\prime}^{\prime}$ phase starts to form, slightly increases with the test temperature but the behavior remains similar to the one shown figure $2 \mathrm{~b}$. Whether the curve will be superelastic or pseudoplastic depends thus not only on the temperature but also on the maximum strain reached. At even higher test temperatures $T>460 \mathrm{~K}$, the fully strained $\gamma_{1}^{\prime}$ phase undergoes reverse MT even upon unloading and the crystal exhibits fully pseudoelastic behavior, though a strongly asymmetric one, in both tension and compression.
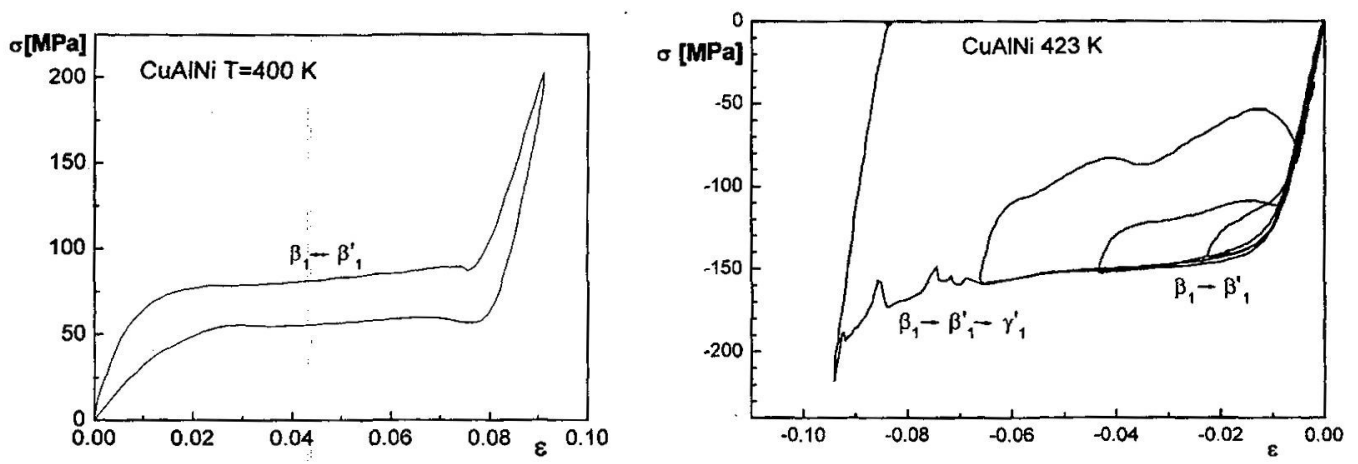

Figure 2: Stress-strain curve of CuAINi single crystal a) deformed at $\mathrm{T}=400 \mathrm{~K}$ in tension, b) deformed at 423 $\mathrm{K}$ in compression.

The stress-strain curves measured at lower temperatures below $T<380 \mathrm{~K}$ are not sensitive to the test temperature but depend significantly on the starting phase and on the loading history (it might be $\beta_{l}$ austenite, selfaccomodated $\beta_{l}^{\prime}$ martensite, $\beta_{l}^{\prime}$ deformed in tension, $\gamma_{l}^{\prime}$ deformed in tension or compression). In the case of single variant $\beta_{1}^{\prime}$ ' martensite deformed in tension, the level of martensite to martensite transformation $\beta_{l}^{\prime} \rightarrow \gamma_{1}$ ' stress plateau is relatively low $(\sigma \sim 50 \mathrm{MPa})$, but for the case of the selfaccommodated $\beta_{l}^{\prime}$ martensite, the stress level is at least twice as high $(\sigma \sim 120 \mathrm{MPa})$.
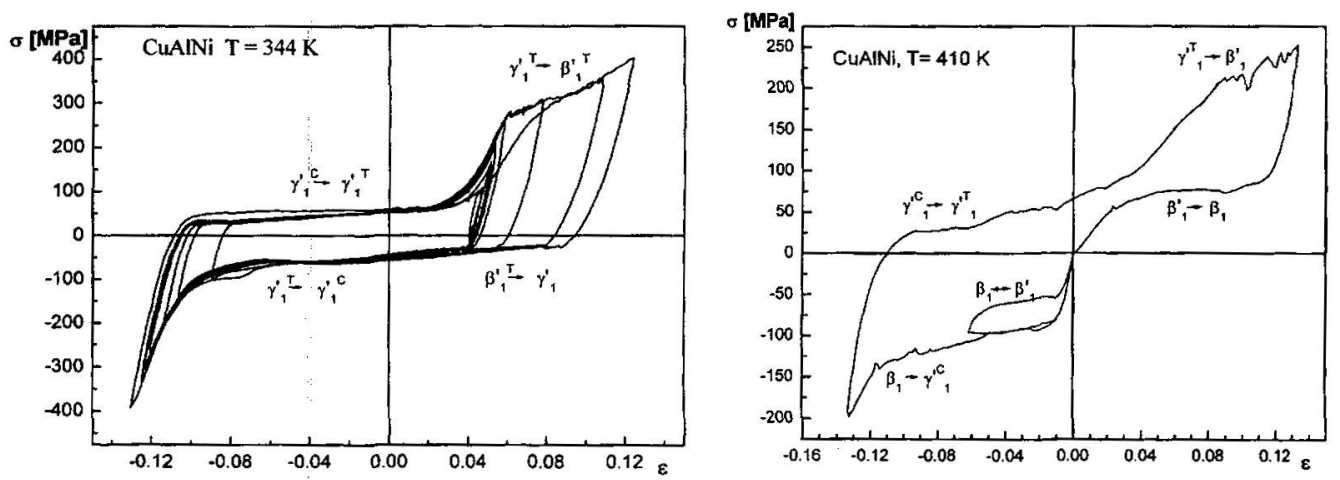

Figure 3: Stress-strain curve of CuAlNi single crystal deformed at $295 \mathrm{~K}$. a) load cycle in the range from \pm 100 $\mathrm{MPa}$ to $\pm 400 \mathrm{MPa}, \mathrm{b}$ ) load cycle at $410 \mathrm{~K}$.

When compression stresses $\sigma>200 \mathrm{MPa}$ are applied, the $\gamma_{l}^{\prime}$ martensite forms eventually both upon stressing and cooling, regardless of the starting state of the specimen. Fig.3a shows cyclic stressstrain response of the crystal at $T=344 \mathrm{~K}$ loaded between two symmetric stress limits $+/-\sigma^{\text {lim }}$ starting from the $\gamma_{l}$ ' martensite. The limits were subsequently increased from $\pm 100 \mathrm{MPa}$ up to $\pm 400 \mathrm{MPa}$. While only reorientation of the $\gamma_{I}$ ' martensite was observed up to the $\sigma^{l i m}=250 \mathrm{MPa}$, above this level, the $\gamma_{1}$ ' 
started to transform to the $\beta_{1}$ ' martensite in tension. The mixture of $\beta_{l}$ 'and $\gamma_{I}$ ' martensites obtained consequently upon unloading from tension transforms to the $\gamma_{1}$ ' martensite upon reloading in compression. The cyclic tension/compression response was independent on the temperature at $T<380 \mathrm{~K}$ but suddenly changed to what can be seen in Fig. $3 \mathrm{~b}$ at higher temperatures $380 \mathrm{~K}<T<420 \mathrm{~K}$. Notice that the starting $\beta_{I}$ austenite phase can be fully recovered by loading in tension above $300 \mathrm{MPa}$ and unloading. At even higher temperatures, an asymmetric pseudoelastic loop in both tension and compression was observed.

The stress-strain behaviour described in Figures 2 and 3 is practically identical to what we have reported for $\mathrm{Cu}-14.3 \mathrm{Al}-4.1 \mathrm{Ni}[\mathrm{wt} . \%]$ studied earlier $[4,5,6,9]$ especially concerning the shape of the pseudoelastic loops, transformation strains and temperature dependence of transformation stresses. What is different is that the test temperatures to study the same phenomena are $200 \mathrm{~K}$ higher, and that the thermally induced martensite phase is not the $\gamma_{1}$ ' but the $\beta_{1}^{\prime}$ 'phase.

\subsection{Construction of the $\sigma-T$ non-equilibrium diagram}

The non-equilibrium stress-temperature diagram constructed from the experimental data is shown in Fig.4a. In brief, the transformation lines $\beta_{I} \leftrightarrow \beta_{l}$ ' were determined from stress-strain cycles and thermal load cycles under constant applied stress. In case of compressive part of the diagram partial cycling was used. Transformation line $\beta_{I} \rightarrow \gamma_{I}$ ' was estimated as its experimental determination is very complicated. We assume, in analogy to other CuAlNi alloys, that the slope of this line is lower compared to the one for the $\beta_{I} \rightarrow \beta_{I}$ ' transformation. The underlying reasons are the equal transformation entropy for both transitions $[9,11]$ and the larger transformation strain in compression, $\varepsilon^{t r}\left(\gamma_{I}^{\prime}\right)>\varepsilon^{t r}\left(\beta_{I}^{\prime}\right)$, for the [001] orientation of the load axis. [5] The nearly horizontal reorientation lines were also determined from stress-strain tests. There is no well defined stress plateau corresponding to the $\gamma_{1}{ }^{\prime} \rightarrow \beta_{l}^{\prime}$ 'transformation in tension and the line denoting this transition is thus only approximated. Similarly, the reverse $\beta_{I}{ }^{\prime} \rightarrow \gamma_{I}$ '
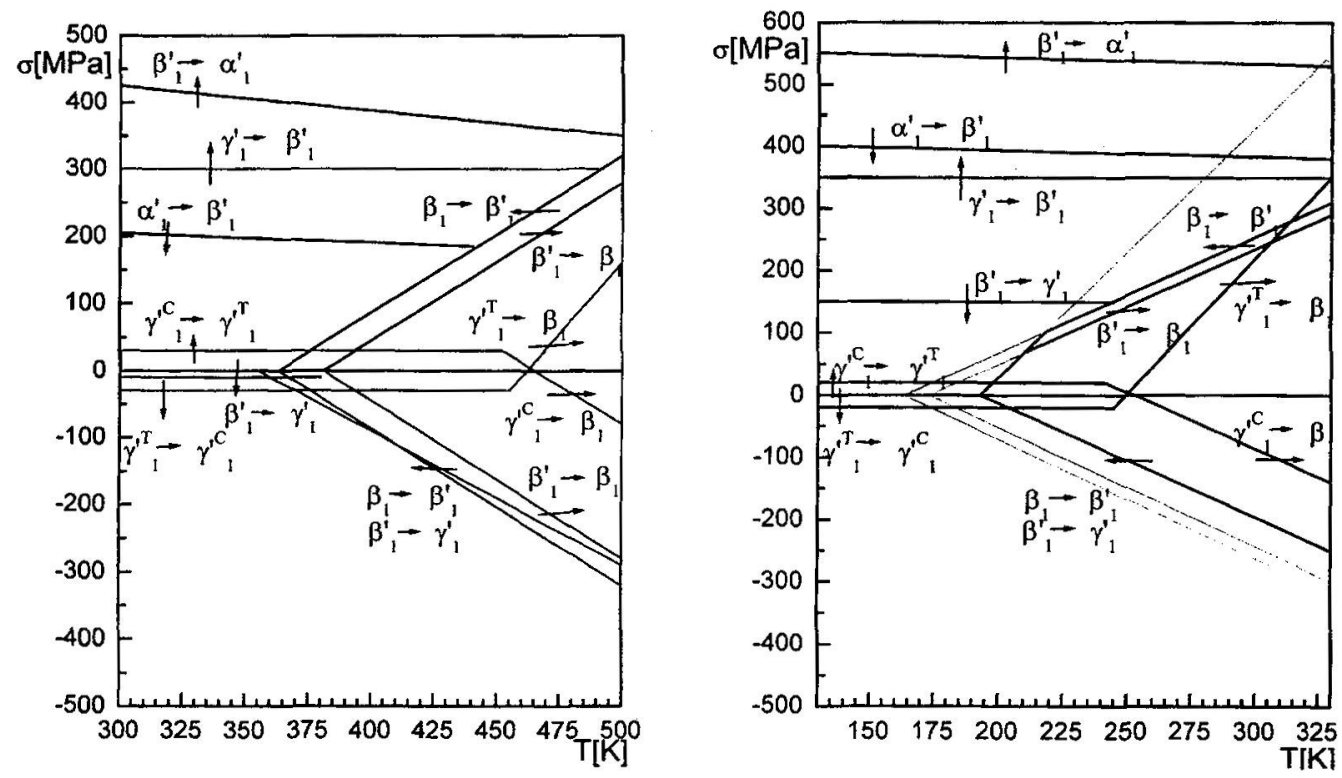

Figure 4: Stress-temperature phase diagrams of [001] CuAlNi single crystal a) Cu-13.4 Al - 4.0 Ni [wt.\%] high temperature alloy, b) $\mathrm{Cu}-14.3 \mathrm{Al}-4.1 \mathrm{Ni}[\mathrm{wt} . \%]$ low temperature alloy

transformation takes place near the zero stress either in tension or compression depending on the history and the corresponding line in Fig. 4a approximates the most frequently encountered case.

The $\sigma-T$ diagram is an extremely useful tool for tracking down the otherwise very complex history dependent responses of the single crystals transforming into two or more martensite phases. The actual 
choice of the transformation path [5] depends on the magnitude of stress, temperature, orientation of the load axis and on the sense of load. It is helpful to identify regions of existence ( $\sigma, T$ conditions at which given solid phase may exist) and regions of stability ( $\sigma, T$ conditions at which given solid phase exists regardless of history) of all individual phases in the diagram [7]. In the $\sigma-T$ diagram in Fig. 4a, there are only three regions where some of the solid phases are stable. They can be distinguished as region I $-y_{l}$ ' martensite in compression, region II- $\beta_{l}$ austenite at highest temperatures and low stress level in both tension and compression, and region III $-\alpha_{l}^{\prime}$ martensite at very high tensile stresses. The $\beta_{1}$ ' martensite phase lacks any region of the stability at all. In the remaining large part of $\sigma-T$ space, more than one phase can be observed depending on the stress-temperature history. The history dependent effects affect at these stresses and temperatures significantly the macroscopic $\sigma-\varepsilon-T$ behaviors. An important point for the high temperature applications is that, if the temperature is limited below say $\mathrm{T}<460 \mathrm{~K}$ from any reason, the $\beta_{l}$ austenite phase also would lack any region of stability, in spite of the fact that the $A_{f}$ temperature of the alloy would be referred as $A_{f}=371 \mathrm{~K}$.

\section{DISCUSSION}

The shift of the $\sigma-T$ diagram upward in the temperature scale with decreasing $\mathrm{Al}$ content is clearly demonstrated in figure 4. Equilibrium temperatures $T_{0}$ of both $\beta_{l} \rightarrow \beta_{1}^{\prime}(220 \mathrm{~K} / 1 \mathrm{wt} \%$ of $\mathrm{Al})$ and $\beta_{l} \rightarrow \gamma_{l}^{\prime}$ $(180 \mathrm{~K} / 1 \mathrm{wt} . \%$ of $\mathrm{Al})$ transformations shift upward with decreasing Al content but not equally $[11,12]$. The difference in the shift rates for both transformations explains why the $\beta_{l}^{\prime}$ ' martensite forms in alloys with lower $\mathrm{Al}$ content' (below 13,6 wt.\%), while the $\gamma_{1}{ }^{\prime}$ phase occurs in alloys having higher $\mathrm{Al}$ content upon stress free cooling. Generally, the non equal shift of the $T_{0}$ temperatures with the composition leads to the shift of the triple point between $\beta_{l}, \beta_{l}^{\prime}$ and $\gamma_{l}{ }^{\prime}$ phases in the diagram. This leads to the significant up or down shifts of the transformation lines for the martensite to martensite transformation $\beta_{1}$ ' $\leftrightarrow \gamma_{1}$ ' and establishment of either the $\beta_{l}^{\prime}$ or $\gamma_{I}^{\prime}$ as the thermally induced martensite phase. Except for this, however, the enormous shift of the diagram in the temperature scale remains to be the dominant effect of the composition change.

The $\sigma-\varepsilon-T$ hysteretic responses of the CuAlNi alloy [001] single crystals in thermomechanical loads hence remain qualitatively similar for both low $\mathrm{Al}$ and high $\mathrm{Al}$ content alloys. $\beta^{\prime}$ martensitic phase is typically induced in tension, $\gamma_{l}$ ' phase in compression and the phase that appears upon stress free cooling or cooling under small stress depends on the composition, magnitude and sense of the small applied stress. The $\gamma_{1}$ ' phase can transform either to the $\beta_{1}^{\prime}$ martensitic phase upon loading in tension or may transform to the austenite phase upon heating. The $A_{f}$ temperature from the deformed $\gamma_{l}^{\prime}$ martensite phase is, however, about $80 \mathrm{~K}$ higher than the $A_{f}$ temperature from the $\beta_{l}^{\prime}$ martensitic phase. When the crystal is deformed in low temperature state in compression and unloaded, its reverse transformation temperature consequently shifts significantly upwards (Fig. 1). This evidently has nothing to do with the martensite stabilization. It is just a simple consequence of the $\beta_{l}^{\prime} \rightarrow \gamma^{\prime}$ transformation upon compression loading and of the wider hysteresis of the $\gamma^{\prime}$ phase (i.e. effect of the thermomechanical history). Similar history dependent phenomena are frequently encountered in single crystal experiments and easily understandable with the help of the $\sigma-T$ diagrams.

In engineering polycrystalline alloys with randomly oriented grains, the history dependent phenomena are inevitably smeared out due to the stress state dependence of the transformation events. The diagrams in Fig. 4a,b apply only for 001 oriented crystals. For other crystal orientations, the $\sigma-T$ diagrams look completely different (see orientation dependence of $\sigma-T$ diagrams in [5]). Pseudoelastic response of Cubased SMA polycrystals is being in the literature typically ascribed to the more frequently encountered $\beta_{l}^{\prime}$ phase in tension, in spite of the fact that the $\gamma_{l}$ ' phase has, in fact, much wider region of stability compared to the $\beta_{I}$ ' phase for most of the crystal orientations [4]. While consideration of only the $\beta_{I}$ ' phase for polycrystals may be justifiable for small strains (note (Fig. 3) that $\beta_{1}$ ' preceded the $\gamma_{1}$ ' formation even in compression), for large strains and mainly in compression, formation of the $\gamma_{l}$ ' phase in polycrystals is equally probable and shall be considered. We have recently proposed a crystallographic model of SMA 
polycrystals [13] based on the theoretical calculation of the $\sigma-T$ diagrams that can deal with anisotropies and multiple martensite phase formation.

Assuming the formation of wider hysteresis $\gamma_{I}^{\prime}$ phase in thermomechanical loads, the history dependent phenomena may pose a real problem for the high temperature Cu-based SMA's, since their usage may be limited from the upper temperature side by other factors (decomposition of austenite, dislocation slip etc.). If the upper temperature limit is not at least $80 \mathrm{~K}$ above the $A_{f}$ temperature of the alloy (from DSC test), the history dependent formation of the $\gamma_{l}$ ' phase and impossibility to restore fully the austenite phase upon heating, would apparently equal to the deteriorating effect of the martensite stabilization (well known for $\mathrm{CuZnAl}$ alloys) destroying the shape memory property of the specimen.

\section{CONCLUSIONS}

Martensitic transformations in $\mathrm{Cu}-13.4 \mathrm{Al}-4.0 \mathrm{Ni}$ [wt.\%] alloy [001] oriented single crystal $\left(\mathrm{M}_{\mathrm{s}}=365 \mathrm{~K}\right)$ were investigated by tension/compression thermomechanical cycling. The non-equilibrium $\sigma-T$ diagram was constructed from the experimental data and compared with the diagram of the $\mathrm{Cu}-14.3 \mathrm{Al}-4.1 \mathrm{Ni}$ [wt.\%] $\left(\mathrm{M}_{\mathrm{s}}=240 \mathrm{~K}\right)$ studied earlier.

It was found that, in spite of the facts that different martensite structures form upon cooling in both alloys and transformation temperatures are $\sim 100 \mathrm{~K}$ different, the stress-strain-temperature responses of both crystals (characterized well by the corresponding non-equilibrium diagrams) are in fact quite similar. It is pointed out that some of the apparent shifts of the $A_{f}$ temperature of $\mathrm{Cu}$-based alloys can be easily understood as a consequence of the history dependent formation mechanism and larger stability of the wide hysteresis $\gamma_{l}$ ' phase compared to the $\beta_{l}$ ' phase.

\section{Acknowledgements}

The financial supports of the Grant Agency of the Academy of Sciences of the Czech Republic under contract no. A1010909 and Czech Ministry of Education under contract No. ME186 are greatly acknowledged.

\section{References}

1. J. van Humbeeck, Journal of Engineering Materials and Technology ASME 121, 98 (1999).

2. E. Cingolani, J. van Humbeeck, M. Ahlers, Met. Mat. Trans. 30A, 493 (1999).

3. C. Qingfu, I Hurtado, R. Stalmans, J. van Humbeeck, J. Phys. IV, C2, 181 (1995).

4. V.Novák and P.Šittner, J. de Phys. IV, C5 227 (1997).

5. V. Novák, P. Šittner, D. Vokoun, N. Zárubová, Mat. Sci Eng. A273-275, 280 (1999).

6. P. Šittner, V. Novák, Journal of Engineering Materials and Technology ASME 121, 48 (1999).

7. P. Šittner, V.Novák, N.Zárubová, Acta Materialia, 46, 1265 (1998).

8. K. Otsuka, H. Sakamoto and K Shimizu, Acta Met. 27, 585 (1979).

9. V.Novák, P.Šittner, N.Zárubová, Mat. Sci. Eng. A, A234-236, 414 (1997).

10. H. Kato, R. Stalmans, J. van Humbeeck, Mat. Trans. JIM 39, 378 (1998).

11. C.M. Friend, Ll. Manosa, J. Ortin, A. Planes, J. de Phys. IV, Colloque C4, 71 (1991).

12. V. Recarte, R.B. Perez-Saez, E.H. Bocanegra, M.L. No, J. San Juan, Mat. Sci. Eng. A273275, 380 (1999) .

13. P. Sittner and V. Novák, International Journal of Plasticity, in print (2000), 